\title{
Study of the microhardness and erosive wear behavior of organo-modified nanoclay filled glass-epoxy composites and optimization
}

\author{
Z Shanti Kiran ${ }^{1}$, V Suresh Babu ${ }^{2}$, KVL Soma Sekhar ${ }^{3}$ \\ ${ }^{1}$ Research Scholar' in Mechanical Engineering, National Institute of Technology Warangal, \\ Telangana, India \\ Phone: +91-9177756772 \\ *Email:skshantikiran@gmail.com \\ ${ }^{2}$ Faculty of Mechanical Engineering, National Institute of Technology \\ Warangal Telangana, India \\ ${ }^{3}$ Faculty of Mechanical Engineering, Vasireddy Venkatadri Institute of technology Guntur, \\ Andhra Pradesh, India
}

\begin{abstract}
This research concentrates on examination and optimization of microhardness and erosion resistance of epoxy-glass-nanoclay composites (EGCN). The parameters considered were the weight content of Cloisite 15A $(A)$, the volume of glass fiber $(B)$, and the direction of glass fibers $(C)$. Hand lay-up technique was used to make the composites and these composites were tested for microhardness and erosive wear rate as per ASTM standards. The L9 orthogonal array was utilized to design microhardness tests and erosive wear tests, and it was observed that the composite with high clay content, low fiber volume, and $45^{\circ}$ orientation showed low erosion rate $\left(E_{r}\right)$ even though its hardness was lower than the optimized value. At the optimum composition corresponding to the lowest $E_{r}$, further erosion studies were conducted with L18 orthogonal array for optimizing machine testing parameters. Scanning electron microscopy (SEM) was used to explain the effect of each parameter on the output. This research looks at the consolidated effect of $A, B$, and $C$ on the erosion resistance of the EGCNs and the effect of testing parameters.
\end{abstract}

Keywords: Nanoclay; Taguchi; surface morphology; solid particle erosion; composites; erosion resistance; optimization; Cloisite 15A.

\section{INTRODUCTION}

Fiber-reinforced polymers (FRP) with high strength and modulus have been replacing traditional materials like wood, plastics, and metals, etc. over the last two decades[1, 2]. In general, the FRPs always had their useful applications in severe working environments as in load-bearing structures, wind turbine blades, pipelines carrying sand slurries in petroleum refining and transportation of airborne solids through pipes and in coal-mine plants, helicopter rotor blades pump impeller blades, high-speed vehicles, water turbines, and aircrafts operating in desert environment, etc. In addition to the high strength to weight ratio, the erosive wear behavior of the FRPs is also of vital importance because it is possible to 
encounter erosive wear in the applications mentioned above, because of which the importance of this type of wear is progressively increasing [3, 4].

Biswas et al. [5] reported $80 \%$ increase in microhardness of the epoxy-glass composite (GRE) with the addition of micro red mud particles. Mohapatra et al. [6] reported $82.7 \%$ increase in microhardness by adding micro TiC particulates in GRE. Mahapatra et al. [7] reported $21.8 \%$ increase in microhardness with the addition of $50 \mathrm{wt} \%$ of glass fiber in polyester resin. Harsha et al. [8] also reported a good increase in microhardness with addition of micro $\mathrm{Al} 2 \mathrm{O} 3$ particles in the polyester matrix. In general, the improvement in hardness of any material results in enhanced wear resistance. Chelladurai et al. [9] reinforced a wire mesh made of steel into LM6 Al-alloy and reported 54.4\% rise in hardness at the interface compared to matrix. Chelladurai et al. [10] reported that the reinforcement of wire mesh made of steel with $\mathrm{Zn}$ coated resulted in $683.3 \%$ rise in hardness at the interface compared to matrix. The increase in hardness is attributed to the mixing of zinc with Al-alloy matrix forming a hard solid solution at the interface resisting the plastic deformation induced by the indenter.

Chelladurai et al. [10-12] explained that when the indenter was pressed against the composite, it will easily propagate through the matrix and as the interface approaches, there will be an increase in resistance to the propagation once the fiber is reached there will be very high resistance as the fiber is the hardest phase. Chelladurai et al. [12] reported $60 \%$ rise in hardness at the interface when the wire mesh made of high strength steel coated with copper in reinforced into LM13 Al-alloy. The LM13 Al-alloy reinforced with a wire mesh of Cu coated steel resulted in significantly decreased sliding wear rate [13]. With increased reinforcement content, the wear rate reduced while the coefficient of friction also had decreased. The surface morphology after the wear test showed finer and smoother grooves indicating enhanced resistance to wear $[9,12]$. There was $26 \%$ decrease in coefficient of friction when $10 \mathrm{wt} \%$ of $\mathrm{Cu}$ coated steel wire mesh was reinforced in LM6 Al-alloy,anda57\% decrease in weight loss [11]. There was a 30.5\% decrease in coefficient of friction when a steel wire mesh coated with Zn was embedded into LM6 Al-alloy and there was 17\% decrease in weight loss too. The surface morphology after wear test showed deeper, longer, and continuous grooves for unreinforced Al-alloy, whereas finer and smoother grooves formed for composite indicated enhanced resistance to wear [10].

Erosive wear of FRPs is usually higher than that of unreinforced polymers. Therefore, efforts have been made to improve the erosion resistance of FRPs by adding particulate fillers [14]. Briscoe et al. [15] reported that reinforcing hard phase into the soft matrix phase enhances the hardness thereby enhancing wear resistance also. Numerous researchers have been investigating the characteristics of FRPs subjected to solid particle erosion conditions. Miyazaki et al. [16] considered the impact of interface strength, fiber materials, matrix materials, impact velocity, and angle of hitting on the solid particle erosion characteristics of FRPs. They noticed inverse proportionality between the Er of FRP's and the interface strength. The same group additionally conducted another comparative study on the erosion characteristics of FRPs with short fiber reinforcements and found that Er is larger in FRPs than in a neat resin, and the Er of FRPs decreases with the decrease of fiber content [17]. Harsha et al. [18] investigated the impact of impingement angle and stream speed on solid particle erosion of different polyaryletherketones and their composites with short fiber reinforcement and concluded that GFRPs are undergoing high erosion compared to neat resin. As the fiber content is increased Er also increased proportionally. 
So far the research in the area of erosive wear of epoxy-glass composites (GFRP) was carried out by various researchers, namely, Miyazaki et al. [16], Fouad et al. [19], Harsha et al. [8], Bagci et al. [20], etc. Research on the erosive wear behavior of GFRP reinforced with various micro and nanofillers was also done. The effect of addition of micro tungsten carbide (WC) particles on erosive wear behaviour of GFRP was studied by Mohan et al. [21]; similarly the effect of micro red mud particles was studied by Biswas et al. [5] while the effect of micro boric acid powder was studied by Bagci et al. [22]; the effect of micro Al2O3 and $\mathrm{SiO} 2$ particles was studied by Bagci et al. [23]; the effect of Cloisite 25A nanoclay particles was studied by Kumar et al. [24] etc. Further, various researchers worked on the mechanical properties of EGCN by adding various organic modified nanoclays and reported considerable improvement in the mechanical properties [25]-[30]. But very few authors have reported the erosion of EGCNs, studies on which are limited and ongoing. Also, limited literature is available on the combined effect of continuous fiber reinforcement, clay nanofiller as a secondary reinforcement, and the orientation of continuous fibers. Based on the given background, an attempt is made in this work to examine the effect of nanoclay loading (A), glass fiber loading (B), and angle of glass fibers orientation (C) on the microhardness and erosion resistance of EGCN. The EGCN with optimized microhardness is tested for erosion characteristics with the aim of optimizing erosion testing parameters.

\section{MATERIALS AND METHODS}

\section{Materials and properties.}

The materials selected are bi-directional woven E-glass fiber mat of $380 \mathrm{gsm}$, epoxy resin of grade LY 556, with triethylenetetramine used as hardener. Cloisite 15A (C15A) is a surface treated montmorillonite nanoclay particles with alkyl ammonium ions and is utilized as nanofiller. Physical Properties of the epoxy resin, hardener, and Cloisite 15A are given in Table 1, Table 2, and Table 3, respectively.

Table 1. Properties of epoxy resin.

\begin{tabular}{cc}
\hline Characteristic & Specification \\
\hline Viscosity at $25^{\circ} \mathrm{C}$ & $10,500 \mathrm{mPas}$ \\
Epoxy Content & $185 \mathrm{~g} / \mathrm{eq}$ \\
Density at $25^{\circ} \mathrm{C}$ & $1.20 \mathrm{~g} / \mathrm{cc}$ \\
Flash Point & $>200^{\circ} \mathrm{C}$ \\
\hline
\end{tabular}


Table 2. Properties of Triethylenetetramine

\begin{tabular}{cc}
\hline Characteristic & Specification \\
\hline Viscosity at $25^{\circ} \mathrm{C}$ & $\sim 20 \mathrm{mPas}$ \\
Density at $25^{\circ} \mathrm{C}$ & $0.98 \mathrm{~g} / \mathrm{cc}$ \\
Flash Point & $115^{\circ} \mathrm{C}$ \\
\hline
\end{tabular}

Table 3. Properties of Cloisite 15A.

\begin{tabular}{cccccc}
\hline $\begin{array}{c}\text { Organic } \\
\text { modifier }\end{array}$ & $\begin{array}{c}\text { Modifier } \\
\text { concentration }\end{array}$ & $\begin{array}{c}\% \\
\text { moisture }\end{array}$ & $\begin{array}{c}\% \\
\text { weight } \\
\text { loss on } \\
\text { ignition }\end{array}$ & Density & $\begin{array}{c}\text { Particle } \\
\text { size }\end{array}$ \\
\hline $\begin{array}{c}\text { Dimethyl } \\
\text { dihydrogenated } \\
\text { tallow } \\
\text { quaternary } \\
\text { ammonium }\end{array}$ & $\begin{array}{c}125 \text { meq/100 } \\
\text { gms of clay }\end{array}$ & $<2 \%$ & $43 \%$ & 2.8 & $<80 \mathrm{~nm}$ \\
& & & & & \\
\hline
\end{tabular}

\section{Preparation of Composites}

The epoxy-clay mixture was prepared by mixing a calculated quantity of epoxy and C15A by stirring at $3000 \mathrm{rpm}$ using a mechanical stirrer for about $1 \mathrm{hr}$. The hardener was added to the prepared mixture in proportions of 10 parts per 100 parts of epoxy resin and stirred further for 5 minutes for uniform mixing.

Table 4. Composite composition ranges.

\begin{tabular}{cc}
\hline Test Parameters & Ranges \\
\hline Nanoclay wt $\% .(A)$ & $0.5-2.5$ \\
Glass fiber volume $\%(B)$ & $10.5-31.5$ \\
Fiber Orientation $(C)$ & $+45^{\circ} /-45^{\circ}-90^{\circ} / 0^{\circ}$ \\
\hline
\end{tabular}




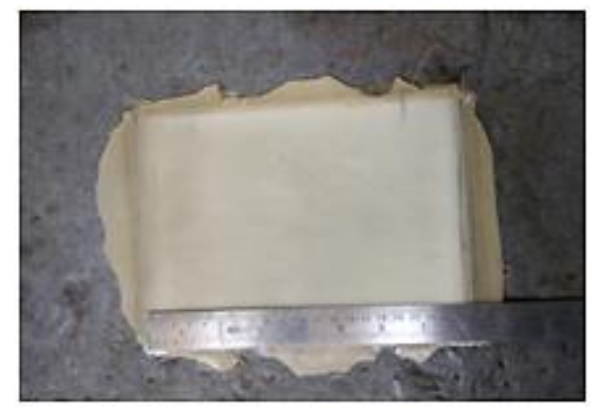

Figure 1. Composite plate of prepared EGCN.

Hand lay-up method was adopted to fabricate the composites. The resin-clay-hardener mixture was coated on fiber sheets and placed one upon another until the required thickness was achieved and the mold was closed by applying constant pressure until the curing was done over in about $24 \mathrm{hrs}$. The prepared composite plate is shown in Figure 1. The parameters and levels selected for this study are given in Table 4. The parameter ranges were selected based on the trial experiments performed to identify the effective ranges. Beyond the given ranges of nanoclay content and glass fiber volume, the hardness decreased. The test specimens were cut in the sizes of $2.5 \mathrm{~mm}$ x $2.5 \mathrm{~mm} \times 4 \mathrm{~mm}$ from the prepared composites.

\section{X-ray diffraction (XRD)}

XRD was performed for OMMT powder, epoxy/GF, and epoxy/GF/OMMT composites using X'Pert PRO diffractometer with pure $\mathrm{K}_{\alpha}$ radiation of wavelength $1.54 \mathrm{~A}^{\circ}$, operating at $40 \mathrm{kV}$ and $30 \mathrm{~mA}$. Scanning was performed at $2 \theta$ ranging up to $30^{\circ}$ at a step of $0.05^{\circ}$ per second. The interlayer spacing of OMMT was determined according to Bragg's Equation (n $\lambda$ $=2 \mathrm{~d} \sin \theta)$.

\section{Microhardness}

Microhardness was measured using Leitz microhardness tester according to ASTM E384 standard. The indenter is made of diamond and is in a pyramid shape with $136^{\circ}$ angle faces which is pressed onto the specimen surface with 500 gms load for 10 seconds [31].

\section{Erosion Test}

Solid particle erosion tests were run according to ASTM G76 standard. The erosion test was conducted on anAirjet Erosion Test Rig with model: TE-400-HMI and make: Magnum; the equipment is shown in Fig. 2. The erosion testing equipment has provision for mixing air and sand in a mixing chamber. The mixture is passed through a nozzle where it gets accelerated and comes out with high speed and hits the specimen surface. The erosion of the EGCNs was studied at 2 and $4 \mathrm{gm} / \mathrm{min}$ mass flow rates of sand particles where silica sand is used as erosive medium with the size of the sand particles being $200 \mu \mathrm{m}$. L9 design is selected to optimize the composite parameters to the lowest Er possible; the testing parameters were maintained constant throughout the experiments at $2 \mathrm{gm} / \mathrm{min}, 30^{\circ}$ impinging angle, 2 bar pressure, $1 \mathrm{~min}$ holding period and $30 \mathrm{~mm}$ stand-off distance. At the optimized composition, the erosion test was conducted using L18 design to optimize the erosion testing parameters, shown in Table 5. 


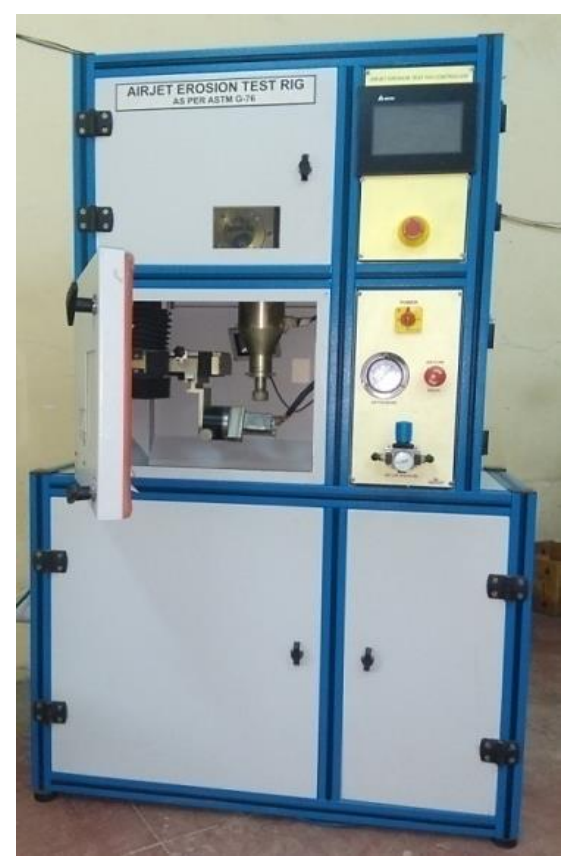

Figure 2. Airjet erosion test rig

Table 5. Erosion testing parameters for L18 design.

\begin{tabular}{cc}
\hline Test Parameters & Ranges \\
\hline Sand Flow Rate (gm/min), $(f)$ & $2-4$ \\
Impingement angle (deg), $(\theta)$ & $15^{\circ}-60^{\circ}$ \\
Air Stream Pressure (bar), $(P)$ & $2-6$ \\
Holding Period (min), $(t)$ & $1-3$ \\
Stand-off distance $(\mathrm{mm}),(d)$ & $10-30$ \\
\hline
\end{tabular}

\section{X-ray diffraction (XRD) analysis}

Figure 3 shows the X-ray diffraction patterns of OMMT, epoxy/GF, and epoxy/GF/OMMT. For OMMT the characteristic peak was observed at $2 \theta=19.8^{\circ}$, and the corresponding $\mathrm{d}$ spacing was $4.5 \mathrm{~nm}$. For the epoxy/GF, no peak was observed as both the epoxy and glass are amorphous materials. For epoxy/GF/OMMT composites the diffraction peaks were observed at $14.4^{\circ}, 14.6^{\circ}, 15.2^{\circ}$ corresponding to $0.5,1.5,2.5 \mathrm{wt} \%$ of OMMT and the corresponding $\mathrm{d}$-spacings were $6.1 \mathrm{~A}^{\circ}, 5.8 \mathrm{~A}^{\circ}, 5.5 \mathrm{~A}^{\circ}$ respectively. The increase in $\mathrm{d}$-spacing of OMMT in composites indicates the epoxy molecules intercalated into the clay layers [28]. It is observed that with an increase in clay content, the d-spacing decreases implying resin intercalation did not occur thereby reducing wetting of clay platelets by resin. 


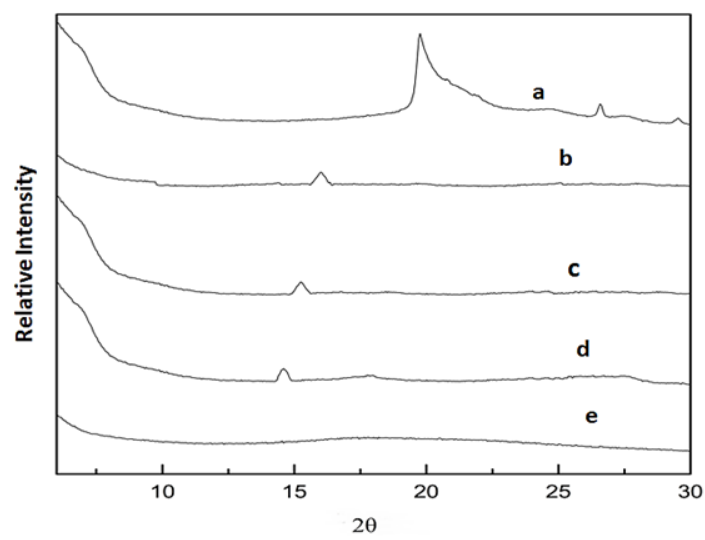

Figure 3. X-ray diffractograms (a) OMMT (b) EGCN with $0.5 w t \%$ OMMT (c) EGCN with 1.5 wt \% OMMT (d) EGCN with 2.5 wt.\% OMMT (e) GRE

\section{Microhardness}

Taguchi method transforms the responses into the $\mathrm{S} / \mathrm{N}$ ratios, which are classified into three types, namely, higher-the-better, lower-the-better, and nominal-the-better. In the present study, for optimizing microhardness, higher-the-better $\mathrm{S} / \mathrm{N}$ ratio suits well as the desired hardness should be as high as possible. Increase in $\mathrm{S} / \mathrm{N}$ ratio implies the response also has increased. $\mathrm{S} / \mathrm{N}$ ratio for the selected quality characteristic is calculated using Eqn. (1).

$$
(S / N)_{H B}=-10 \log \left[\frac{1}{R} \sum_{j=1}^{R}\left(1 / Y_{j}^{2}\right)\right]
$$

In Eqn. (1), ' $R$ ' is the number of times the experiment is repeated [32]. From Table 4, for given three parameters and each with three levels, the suitable orthogonal array available in the Taguchi method is L9. The L9 orthogonal array is shown in Table 6 with given corresponding microhardness and $\mathrm{S} / \mathrm{N}$ ratio values.

Table 6. Experimental design using L9orthogonal array for microhardness.

\begin{tabular}{rrrrrr} 
Expt. No. & $\boldsymbol{A}$ & $\boldsymbol{B}$ & $\boldsymbol{C}$ & Microhardness $(\mathbf{H V})$ & S/N ratio \\
\hline 1 & 0.5 & 10.50 & $45^{\circ}$ & 16.9 & 24.56 \\
2 & 0.5 & 21 & $67.5^{\circ}$ & 18.8 & 25.48 \\
3 & 0.5 & 31.50 & $90^{\circ}$ & 20.1 & 26.06 \\
4 & 1.5 & 10.50 & $67.5^{\circ}$ & 20.7 & 26.32 \\
5 & 1.5 & 21 & $90^{\circ}$ & 20.8 & 26.36 \\
6 & 1.5 & 31.50 & $45^{\circ}$ & 21.3 & 26.56 \\
7 & 2.5 & 10.50 & $90^{\circ}$ & 22.0 & 26.85 \\
8 & 2.5 & 21 & $45^{\circ}$ & 23.0 & 27.23 \\
9 & 2.5 & 31.50 & $67.5^{\circ}$ & 26.7 & 28.53 \\
\hline
\end{tabular}


Figure $4 \&$ Table 7 demonstrate the $\mathrm{S} / \mathrm{N}$ ratio plots and ANOVA results of $\mathrm{S} / \mathrm{N}$ ratios. The parameters $A, B$ had a significant effect on microhardness, and parameter $C$ is insignificant. The maximum hardness is observed at a set of parameters $A 3 B 3 C 1$ from the $\mathrm{S} / \mathrm{N}$ ratio plot. Since the orientation $C$ did not affect, $0^{\circ}$ is chosen arbitrarily for the prediction of the optimum value of hardness. Eqn. (2) is used to calculate the estimated optimum S/N ratio.

From Figure 4, it can be observed that with an increase in nanoclay content (A) and glass fiber content $(\mathrm{B})$ the hardness is increased, whereas the orientation of the fibers in the composite (C) shows negligible effect. ANOVA Table 7 corroborates the results observed from $\mathrm{S} / \mathrm{N}$ ratio plot. When the indenter is pressed on the composite surface, it exerts compressive stress resulting in compaction of clay particles and glass fiber to the epoxy. Thus, the load is transferred effectively below the specimen surface resulting in enhanced hardness of the composite [33]. The effect of fiber content on hardness may be described as follows: increase in fiber volume decreases the volume of matrix correspondingly and fibermatrix interface become close to the indenter, whereby the hardness is increased. The same phenomenon was reported by Mahapatra et al. [7]. The negligible effect of fibers orientation is attributed to the fact that increase or decrease in hardness is based on the load transferred by the matrix which is applied by the indenter and the orientation of fibers does not affect this phenomenon. If the orientation of the fibers is causing changes in hardness, it can only be imputed to the discontinuity of fibers on the surface making the interface of fiber-matrix located at uneven depths from the surface and the load applied by the indenter has also become uneven. The same phenomenon was reported by Alomayri et al. [34].

Table 7. ANOVA for $\mathrm{S} / \mathrm{N}$ ratios of microhardness

\begin{tabular}{cccccccc}
\hline Source & DF & Seq SS & \% Contribution & Adj SS & Adj MS & F-Value & P-Value \\
\hline$A$ & 2 & 7.062 & $72.04 \%$ & 7.0626 & 3.531 & 75 & 0.013 \\
$B$ & 2 & 1.997 & $20.37 \%$ & 1.997 & 0.998 & 21.21 & 0.045 \\
$C$ & 2 & 0.649 & $6.63 \%$ & 0.649 & 0.3249 & 6.9 & 0.127 \\
Error & 2 & 0.094 & $0.96 \%$ & 0.094 & 0.047 & & \\
Total & 8 & 9.804 & $100.00 \%$ & & & & \\
\hline
\end{tabular}




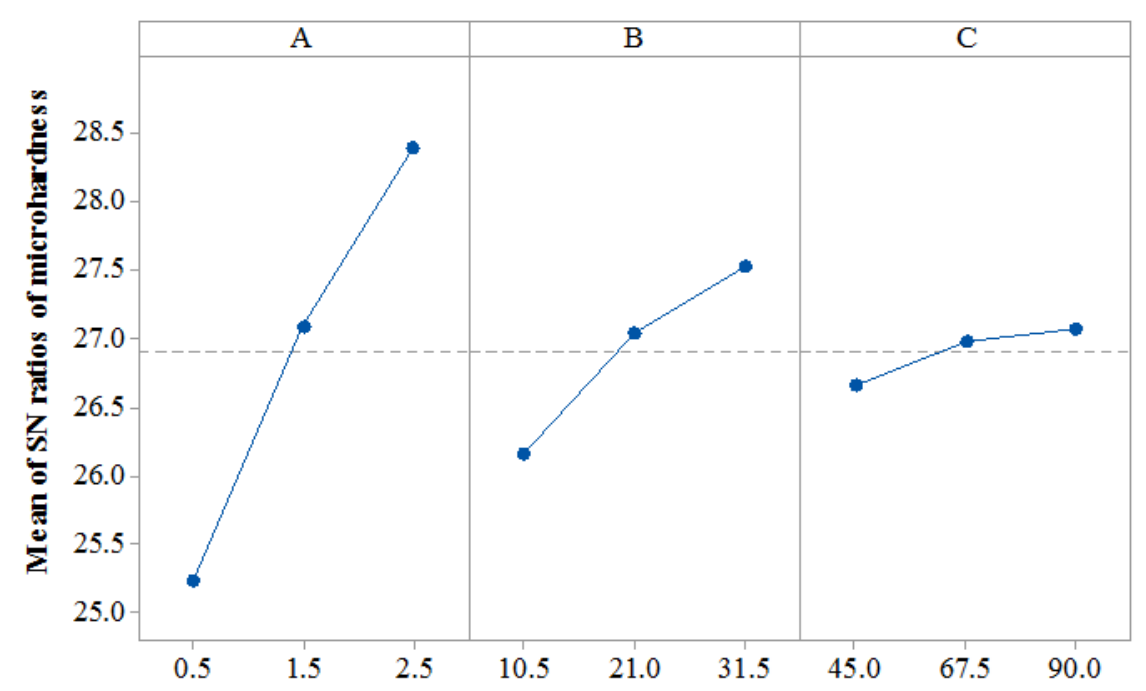

Signal-to-noise: Larger is better

Figure 4.Plots between control factors and $\mathrm{S} / \mathrm{N}$ ratios of microhardness.

$$
\hat{\eta}=\eta_{m}+\sum_{i=1}^{q}\left(\bar{\eta}_{i}-\eta_{m}\right)
$$

Where $\hat{\eta}$ is the predicted $\mathrm{S} / \mathrm{N}$ ratio; $\bar{\eta}_{i}$ is the $\mathrm{S} / \mathrm{N}$ ratio corresponding to the optimum condition; $\eta_{m}$ is the average of all the $\mathrm{S} / \mathrm{N}$ ratios; $\mathrm{q}$ is the number of variables.

$\hat{\eta}=26.9+(28.4-26.67)+(27.52-26.9)+(26.66-26.9)=28.78$

The optimized microhardness is obtained from Eqn. (3).

$$
y_{j}^{2}=1 / 10^{(-\widehat{\eta} / 10)}
$$

The optimized value of hardness is $27.4 \mathrm{HV}$, and the corresponding experimental value is 27.23 HV shown in Table 8. A comparison was made between the hardness obtained at the optimum conditions with the hardness of neat epoxy and also with the hardness of composite made without added nanoclay while fixing the other two parameters under optimum conditions. The microhardness numbers at the conditions mentioned above were evaluated experimentally and obtained as $12 \mathrm{HV}$ and $17.4 \mathrm{HV}$. The improvement in hardness at $A 3 B 3 C 1$ is $127 \%, 56 \%$.

Table 8. Results at the optimum conditions.

\begin{tabular}{ccc}
\hline & \multicolumn{2}{c}{ Optimal Control Parameters } \\
\cline { 2 - 3 } & Prediction & Experimental \\
\hline Level & $A 3 B 3 C 1$ & $A 3 B 3 C 1$ \\
S/N ratio & 28.78 & $28.69 \pm 0.2$ \\
Microhardness (HV) & 27.47 & $27.23 \pm 0.63$ \\
\hline
\end{tabular}




$$
\begin{array}{r}
\text { Microhardness }=21.144-2.544 \mathrm{~A} 1-0.211 \mathrm{~A} 2+2.756 \mathrm{~A} 3-1.278 \mathrm{~B} 1-0.278 \mathrm{~B} 2 \\
+1.556 \mathrm{~B} 3-0.744 \mathrm{C} 1+0.922 \mathrm{C} 2-0.178 \mathrm{C} 3
\end{array}
$$

Eqn. (4) is the general linear model, generated by doing ANOVA analysis using MINITAB software. For validating the model, two composites were prepared under conditions which were not reported in Table 6. The experimental conditions selected are given in Table 9 as also the predicted and experimental results.

\begin{tabular}{|c|c|c|c|c|c|}
\hline \multirow{2}{*}{ Expt. No. } & \multirow{2}{*}{$\boldsymbol{A}$} & \multirow{2}{*}{$\boldsymbol{B}$} & \multirow{2}{*}{$C$} & \multicolumn{2}{|c|}{ Microhardness (HV) } \\
\hline & & & & Predicted & Experimental \\
\hline 1. & 0.5 & 21 & $90^{\circ}$ & 18.14 & $18.5 \pm 0.46$ \\
\hline 2. & 2.5 & 10.50 & 45 & 21.87 & $22.18 \pm 0.72$ \\
\hline
\end{tabular}

Table 9. Results at the optimum conditions

\section{Erosion rate: Optimization of composite parameters}

In this study, the same L9 orthogonal array has been selected as in microhardness evaluation in the previous section. The L9 design and the corresponding $E_{\mathrm{r}}$ values and $\mathrm{S} / \mathrm{N}$ ratios are given in Table 10. For this study, lower-the-better $\mathrm{S} / \mathrm{N}$ ratio was selected and the corresponding equation is shown in Eqn. (5).

$$
S / N_{L}=-10 \log \left[\frac{1}{R} \sum_{j=1}^{R}\left(y_{j}^{2}\right)\right]
$$

Table 10. Experimental design using L9orthogonal array for erosion test.

\begin{tabular}{lccccc} 
Sl. No & $\boldsymbol{A}$ & $\boldsymbol{B}$ & $\boldsymbol{C}$ & Erosion Rate $(\mathbf{m g} / \mathbf{k g})$ & S/N ratio \\
\hline 1. & 0.5 & 10.50 & $45^{\circ}$ & 2318.8 & -67.3053 \\
2. & 0.5 & 21 & $67.5^{\circ}$ & 2827.2 & -69.0271 \\
3. & 0.5 & 31.5 & $90^{\circ}$ & 3416.4 & -70.6714 \\
4. & 1.5 & 10.50 & $67.5^{\circ}$ & 2329.6 & -67.3456 \\
5. & 1.5 & 21 & $90^{\circ}$ & 2648.8 & -68.461 \\
6. & 1.5 & 31.5 & $45^{\circ}$ & 2438 & -67.7407 \\
7. & 2.5 & 10.50 & $90^{\circ}$ & 2205.2 & -66.869 \\
8. & 2.5 & 21 & $45^{\circ}$ & 1994.4 & -65.9962 \\
9. & 2.5 & 31.5 & $67.5^{\circ}$ & 2459.6 & -67.8173 \\
\hline
\end{tabular}




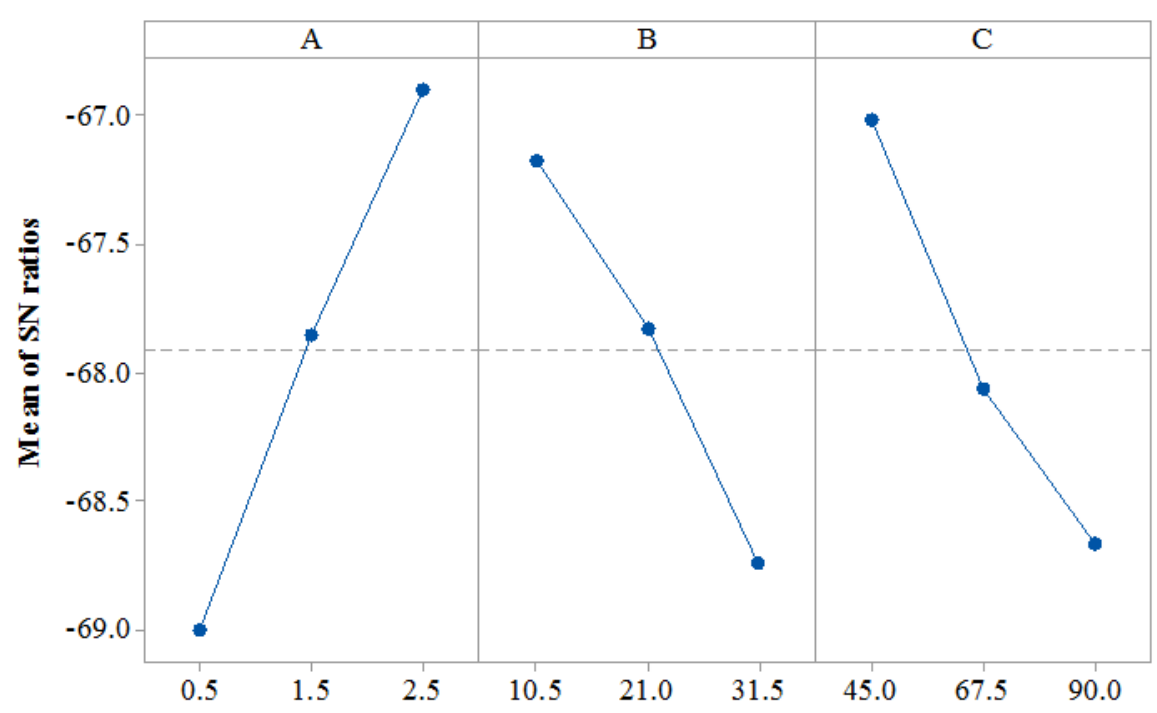

Signal-to-noise: Smaller is better

Figure 5. Plots between control factors and $\mathrm{S} / \mathrm{N}$ ratios of erosive wear rate

From Figure 5 it is obvious that with an increase in clay content, $\mathrm{E}_{\mathrm{r}}$ decreased, whereas, with an increase in glass fiber volume, $\mathrm{E}_{\mathrm{r}}$ increased, and with an increase in angle of fibers in the range $45^{\circ} /-45^{\circ}$ to $90^{\circ} / 0^{\circ}, \mathrm{E}_{\mathrm{r}}$ increased. ANOVA results displayed in Table 11 show that the parameters $A, B, C$ have a significant effect on the erosion of EGCN. The lowest $\mathrm{E}_{\mathrm{r}} \mathrm{is}$ observed at the condition $A 3 B 1 C 1$; under these parameters, the predicted value of $\mathrm{S} / \mathrm{N}$ ratio is calculated using Eqn. (2). The predicted and confirmation experiment results of $\mathrm{E}_{\mathrm{r}}$ values are given in Table 12.

The erosion of fibers has occurred by the induced bending moment due to the action of continuous hitting of the sand particles. The cracks had formed first followed by the breaking of fibers and expulsion of the broken fibers from the erosion zone by air stream pressure. This phenomenon is in contrast to the erosion of the matrix in which the matrix cracks first and fractures into small fragments by the ploughing action of sand particles and hence this process is slow. Therefore, with an increase in fiber volume, the erosion rate is increased which can be observed in figure 5. The reduced wear rate with increase in nanoclay content is attributed to the increased hardness with addition of nanoclay. The specimens with $90^{\circ} 0^{\circ}$ fiber direction exhibited higher $\mathrm{E}_{\mathrm{r}}$ values and the specimens with $45^{\circ}$ $45^{\circ}$ fiberdirection exhibited lower $E_{\mathrm{r}}$ values. When the particles were striking at other than normal angle the composites with $0^{\circ} / 90^{\circ}$ fiber direction were subjected to pure bending moment. In case of the composites with $45 \%$ 
Table 11. Anova table for S/N ratio's of erosion wear rate

\begin{tabular}{cccccccc}
\hline Source & DF & Seq SS & \%Contribution & Adj SS & Adj MS & F-Value & P-Value \\
\hline$A$ & 2 & 6.6792 & $45.61 \%$ & 6.67921 & 3.3396 & 182.59 & 0.005 \\
$B$ & 2 & 3.7304 & $25.47 \%$ & 3.73038 & 1.86519 & 101.98 & 0.01 \\
$C$ & 2 & 4.1981 & $28.67 \%$ & 4.19808 & 2.09904 & 114.76 & 0.009 \\
Error & 2 & 0.0366 & $0.25 \%$ & 0.03658 & 0.01829 & & \\
Total & 8 & 14.6442 & $100.00 \%$ & & & & \\
\hline
\end{tabular}

$45^{\circ}$ fiber direction, the bending moment was in two directions, one normal to the fibers, and the other tangential to the fibers. Hence, the normal bending moment which causes failure is reduced, thereby reducing wear, a phenomenon observed previously by Bagci et al. [22].

Table 12. Results at the optimum conditions.

\begin{tabular}{ccc}
\hline & \multicolumn{2}{c}{ Optimal Control Parameters } \\
\cline { 2 - 3 } & Prediction & Experimental \\
\hline Level & $A 3 B 1 C 1$ & $A 3 B 1 C 1$ \\
$\mathrm{~S} / \mathrm{N}$ ratio & -65.24 & $-65.4 \pm 0.34$ \\
$\mathrm{E}_{\mathrm{r}}(\mathrm{mg} / \mathrm{kg})$ & 1828 & $1865 \pm 72$ \\
\hline
\end{tabular}

A comparison was made between $E_{r}$ obtained under optimum conditions with $E_{r}$ of neat epoxy and also with $\mathrm{E}_{\mathrm{r}}$ of composite made without added nanoclay while fixing the other two parameters at optimum conditions. The $\mathrm{E}_{\mathrm{r}}$ of neat epoxy is $2519 \mathrm{mg} / \mathrm{kg}$ which is $26 \%$ higher and that of the composite without adding nanoclay is $2645 \mathrm{mg} / \mathrm{kg}$ which is $29.5 \%$ higher. The weight loss due to erosion increased with increase in glass fiber volume in the composite, due to the breaking of fibers by means of bending moment, because of the impinging sand particles. As the glass fibers are brittle they broke easily by the bending moment and were expelled from the zone by air [22].

$$
\begin{array}{r}
\mathrm{E}_{\mathrm{r}}=\quad \begin{array}{r}
2515.3+338.8 \mathrm{~A} 1-43.2 \mathrm{~A} 2-295.6 \mathrm{~A} 3-230.8 \mathrm{~B} 1-25.2 \mathrm{~B} 2 \\
+
\end{array} \\
+256.0 \mathrm{~B} 3-264.9 \mathrm{C} 1+23.5 \mathrm{C} 2+241.5 \mathrm{C} 3
\end{array}
$$

Eqn. (6) is the general linear model generated for erosion rate for the design shown in Table 10. It is generated by ANOVA analysis using MINITAB software. For validating the model, two composites were prepared under conditions not included in Table 10. The experimental conditions are given in Table 13 and the predicted and experimental results also figure in Table 13.

Table 13. Results at the optimum conditions.

\begin{tabular}{cccccc}
\hline \multirow{2}{*}{ Expt. No. } & $\boldsymbol{A}$ & $\boldsymbol{B}$ & $\boldsymbol{C}$ & \multicolumn{2}{c}{ Erosion Rate (mg/kg) } \\
\cline { 5 - 6 } & & & & Predicted & Experimental \\
\hline 1. & 0.5 & 21 & $90^{\circ}$ & 3070.4 & $3132.5 \pm 95$ \\
2. & 2.5 & 10.50 & 45 & 1724 & $1789.2 \pm 47$ \\
\hline
\end{tabular}




\section{Erosion rate: Optimization of testing parameters}

From Table 5, for the given five parameters, one with two levels and four with three levels, the suitable orthogonal array available in Taguchi method is L18. The L18 design with obtained $E_{r}$ values is given in Table 14. In this study, the aim is to find the lowest $E_{r}$. Therefore, the required quality characteristic selected is lower-the-better. Eqn. (4) is used to calculate the $\mathrm{S} / \mathrm{N}$ ratios for the selected quality characteristic. Figure 6 shows the $\mathrm{S} / \mathrm{N}$ ratio plot versus parameter levels. Table 15 demonstrates ANOVA results for $\mathrm{S} / \mathrm{N}$ ratios. The significance of the effect of parameters is given in the order as follows: impingement angle, holding time, pressure, and stand-off distance.

The effect of each control factor on $\mathrm{E}_{\mathrm{r}}$ of EGCN can be observed in figure 6 . The optimal level of each parameter corresponds to the higher value of $\mathrm{S} / \mathrm{N}$ ratio respectively. The optimum value of $\mathrm{E}_{\mathrm{r}}$ will occur at the parameter level corresponding to the high $\mathrm{S} / \mathrm{N}$ ratio value. Based on ANOVA analysis it is noted that the air flow rate has a dominant effect over other factors. The other parameters in the order of dominance in effect on $\mathrm{E}_{\mathrm{r}}$ are angle, pressure, holding period, and stand-off distance. The optimal conditions were identified from $\mathrm{S} / \mathrm{N}$ ratio plot and given as $f 1 \theta 1 p 1 t 1 d 3$. The optimal $\mathrm{S} / \mathrm{N}_{\mathrm{L}}$ proportion $\hat{\eta}$ can be calculated using Eqn. (2) and it is obtained as -64.56 and by substituting this predicted optimal S/N ratio in Eqn. (3), the value of predicted $\mathrm{E}_{\mathrm{r}}$ at the optimal conditions can be obtained. The predicted and confirmation test values of $\mathrm{E}_{\mathrm{r}}$ are given in Table 14.

Table 14.Experimentaldesign using L18orthogonal array for erosion test.

\begin{tabular}{cccccccc}
\hline $\begin{array}{c}\text { Expt. } \\
\text { No. }\end{array}$ & $\begin{array}{c}\boldsymbol{f} \\
(\mathbf{g m} / \mathbf{m i n})\end{array}$ & $\boldsymbol{\theta}$ & $\begin{array}{c}\boldsymbol{P} \\
(\mathbf{b a r})\end{array}$ & $\begin{array}{c}\boldsymbol{t} \\
(\boldsymbol{m i n})\end{array}$ & $\begin{array}{c}\boldsymbol{d} \\
(\boldsymbol{m m})\end{array}$ & $\begin{array}{c}\text { Erosion Rate } \\
(\mathbf{m g} / \mathbf{k g})\end{array}$ & $\begin{array}{c}\text { S/N } \\
\text { Ratio }\end{array}$ \\
\hline 1. & 2 & $15^{\circ}$ & 2 & 1 & 10 & 1819.85 & -65.19 \\
2. & 2 & $15^{\circ}$ & 4 & 2 & 20 & 2071.45 & -66.32 \\
3. & 2 & $15^{\circ}$ & 6 & 3 & 30 & 2288.81 & -67.19 \\
4. & 2 & $30^{\circ}$ & 2 & 1 & 20 & 1992.33 & -65.98 \\
5. & 2 & $30^{\circ}$ & 4 & 2 & 30 & 2207.35 & -66.87 \\
6. & 2 & $30^{\circ}$ & 6 & 3 & 10 & 2843.65 & -69.07 \\
7. & 2 & $60^{\circ}$ & 2 & 2 & 10 & 2536.18 & -68.08 \\
8. & 2 & $60^{\circ}$ & 4 & 3 & 20 & 2824.97 & -69.02 \\
9. & 2 & $60^{\circ}$ & 6 & 1 & 30 & 2555.21 & -68.15 \\
10. & 4 & $15^{\circ}$ & 2 & 3 & 30 & 2331.43 & -67.35 \\
11. & 4 & $15^{\circ}$ & 4 & 1 & 10 & 2590.54 & -68.266 \\
12. & 4 & $15^{\circ}$ & 6 & 2 & 20 & 2784.65 & -68.89 \\
13. & 4 & $30^{\circ}$ & 2 & 2 & 30 & 2491.78 & -67.93 \\
14. & 4 & $30^{\circ}$ & 4 & 3 & 10 & 3187.46 & -70.06 \\
15. & 4 & $30^{\circ}$ & 6 & 1 & 20 & 2942.53 & -69.37 \\
16. & 4 & $60^{\circ}$ & 2 & 3 & 20 & 3090.68 & -69.79 \\
17. & 4 & $60^{\circ}$ & 4 & 1 & 30 & 2893.87 & -69.23 \\
18. & 4 & $60^{\circ}$ & 6 & 2 & 10 & 3543.21 & -70.98 \\
\hline
\end{tabular}




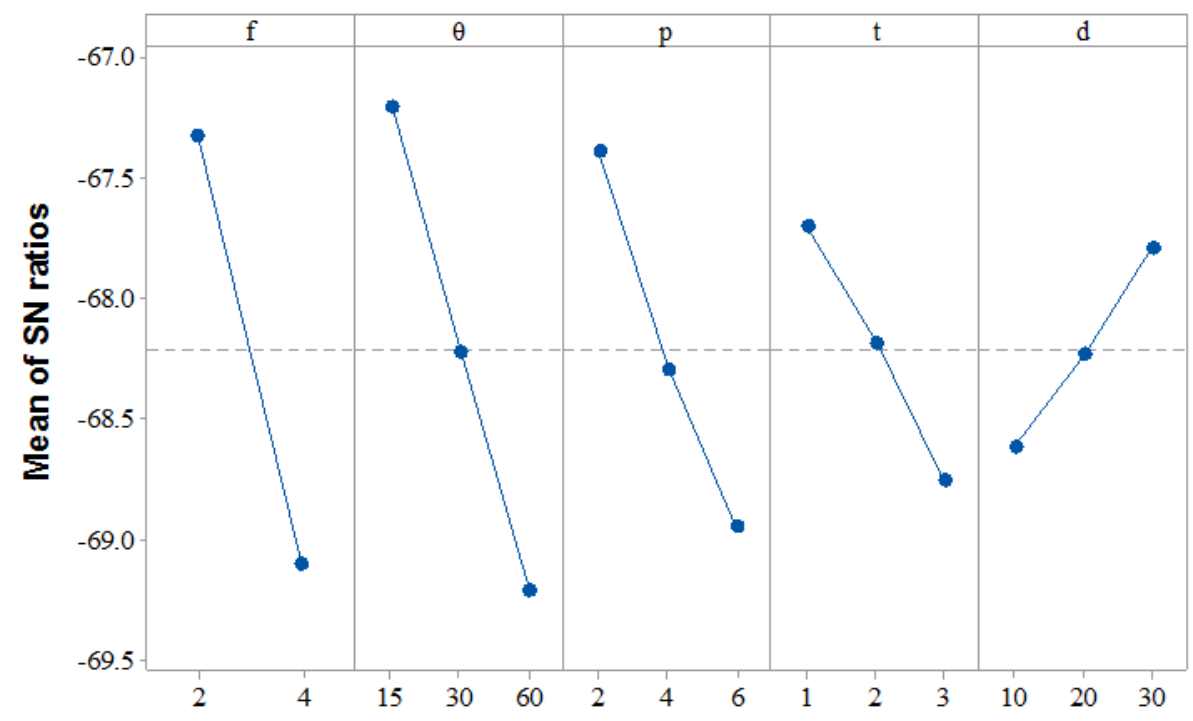

Signal-to-noise: Smaller is better

Figure 6. Plots between testing parameters and $\mathrm{S} / \mathrm{N}$ ratios of erosive wear rate for EGCN with optimized composition

Table 15. Anova table for $\mathrm{S} / \mathrm{N}$ ratio's of erosion wear rate.

\begin{tabular}{cccccccc}
\hline Source & DF & Seq SS & \% Contribution & Adj SS & Adj MS & F & P \\
\hline$f$ & 1 & 14.2167 & $36.27 \%$ & 14.2167 & 14.2167 & 539.75 & 0 \\
$\theta$ & 2 & 12.0847 & $30.83 \%$ & 12.0847 & 6.0424 & 229.40 & 0 \\
$p$ & 2 & 7.3099 & $18.65 \%$ & 7.3099 & 3.655 & 138.76 & 0 \\
$t$ & 2 & 3.3185 & $8.47 \%$ & 3.3185 & 1.6593 & 63.00 & 0 \\
$d$ & 2 & 2.0527 & $5.24 \%$ & 2.0527 & 1.0263 & 38.97 & 0 \\
Error & 8 & 0.2107 & $0.54 \%$ & 0.2107 & 0.0263 & & \\
Total & 17 & 39.1933 & $100.00 \%$ & & & & \\
\hline
\end{tabular}

A comparison was made between the $\mathrm{E}_{\mathrm{r}}$ obtained at the optimum conditions with the $E_{r}$ of neat epoxy and also with the $E_{r}$ of composite made without added nanoclay fixing the other two parameters at optimum conditions. The $\mathrm{E}_{\mathrm{r}}$ of neat epoxy is $2013 \mathrm{mg} / \mathrm{kg}$ which is $21.2 \%$ higher and that of the composite without added nanoclay is $2261.4 \mathrm{mg} / \mathrm{kg}$ which is $29.8 \%$ higher. 
Table 16. Results at the optimum conditions.

\begin{tabular}{ccc} 
& \multicolumn{3}{c}{ Optimal Control Parameters } \\
\cline { 2 - 3 } & Prediction & Experimental \\
\hline Level & $f 1 \theta 1 p 1 t 1 d 3$ & $f 1 \theta 1 p 1 t 1 d 3$ \\
S/N ratio & -64.56 & $-63.99 \pm 0.41$ \\
$\mathrm{E}_{\mathrm{r}}(\mathrm{mg} / \mathrm{kg})$ & 1690.44 & $1586.41 \pm 76$ \\
\hline & $2610.89-262.02 \mathrm{f}_{1}+262.02 \mathrm{f}_{2}-296.43 \theta_{1}-0.04 \theta_{2}$ \\
$+296.47 \theta_{3}-233.84 \mathrm{p}_{1}+18.39 \mathrm{p}_{2}+215.46 \mathrm{p}_{3}-145.16 \mathrm{t}_{1}$ \\
$-5.12 \mathrm{t}_{2}+150.28 \mathrm{t}_{3}+142.60 \mathrm{~d}_{1}+6.88 \mathrm{~d}_{2}-149.48 \mathrm{~d}_{3}$
\end{tabular}

Eqn. (7) is the general linear model generated for the erosion rate for the design shown in Table 14. It is generated by ANOVA analysis using MINITAB software. For validating the model, two composites were prepared under conditions not reported in Table 14. The experimental conditions selected are given in Table 17as also the predicted and experimental results in Table 17.

Table 17. Results at the optimum conditions.

\begin{tabular}{ccccccccc}
\hline & & & & & \multicolumn{2}{c}{ Erosion Rate $(\mathbf{m g} / \mathbf{k g})$} \\
\cline { 5 - 8 } Expt. No. $\boldsymbol{f}(\mathbf{g m} / \mathbf{m i n})$ & $\boldsymbol{\theta}$ & $\boldsymbol{P}(\boldsymbol{b a r})$ & $\boldsymbol{t}(\mathbf{m i n})$ & $\boldsymbol{d}(\mathbf{m m})$ & \multicolumn{2}{c}{ Predicted } & Experimental \\
\hline 1. & 2 & $30^{\circ}$ & 6 & 2 & 20 & 2566.05 & $2620 \pm 82$ \\
2. & 4 & $30^{\circ}$ & 4 & 2 & 20 & 2893.02 & $2945 \pm 98$ \\
\hline
\end{tabular}

\section{Morphology of eroded surfaces}

Figure 7(a) is the SEM image of the tested neat GRE specimens and Figures 7(b) - 7(c) are of EGCN are tested at the fixed erosion testing conditions as follows: $2 \mathrm{gm} / \mathrm{min}, 30^{\circ}$ impinging angle, 2 bar pressure, 1 min holding period, $30 \mathrm{~mm}$ stand-off distance. The mechanism of deformation of the FRPs subjected to erodent particles is as follows; the abrasive particles striking the surface remove the matrix layer first and the fibers are exposed to air stream creating high bending moments on the fibers forming cracks resulting in fracture and ejection of broken fibers forming grooves. If the bombardment persists, it results in the formation of craters. The decreased surface roughness in Figures 7(b) - 7(c) indicates that the composites containing nanoclay demonstrated critical deformation, which means that the nanoclay has good compatibility with the epoxy resin and glass fiber, forming a strong bond between fiber and matrix thereby slowing down the erosion of EGCN. The neat GFRP in Figure 7(a) shows the rough surface which is comparatively rougher than EGCNs shown in Figures 7(b) - 7(c). The size of the broken fiber in Figure 7(b) indicates how fast the failure of the fibers occurred, unlike the matrix which takes more time since it breaks slowly into small debris. In Figure 3, it shows that with an increase in fiber volume $\mathrm{E}_{\mathrm{r}}$ increased. 


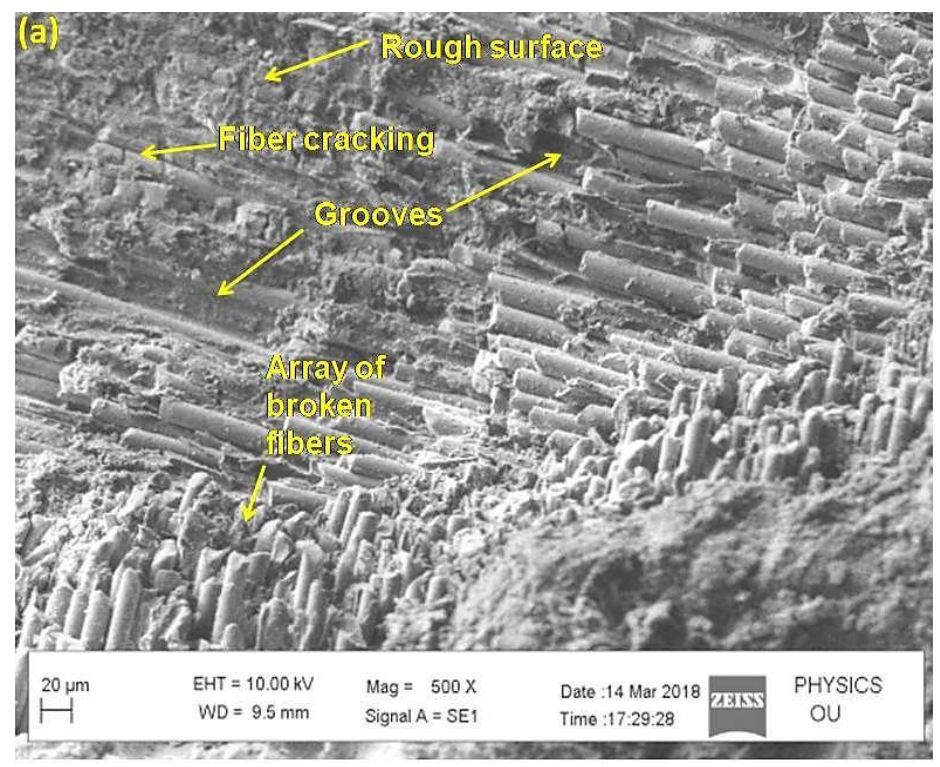

Figure 7(a). SEM image of specimen tested at $2 \mathrm{gm} / \mathrm{min}, 30^{\circ}$ impinging angle, $2 \mathrm{bar}$ pressure, 1 min holding period, $30 \mathrm{~mm}$ stand-off distance for a composition of $0 \mathrm{wt} . \%$, 10.5 vol. $\%, 0^{\circ} / 90^{\circ}$

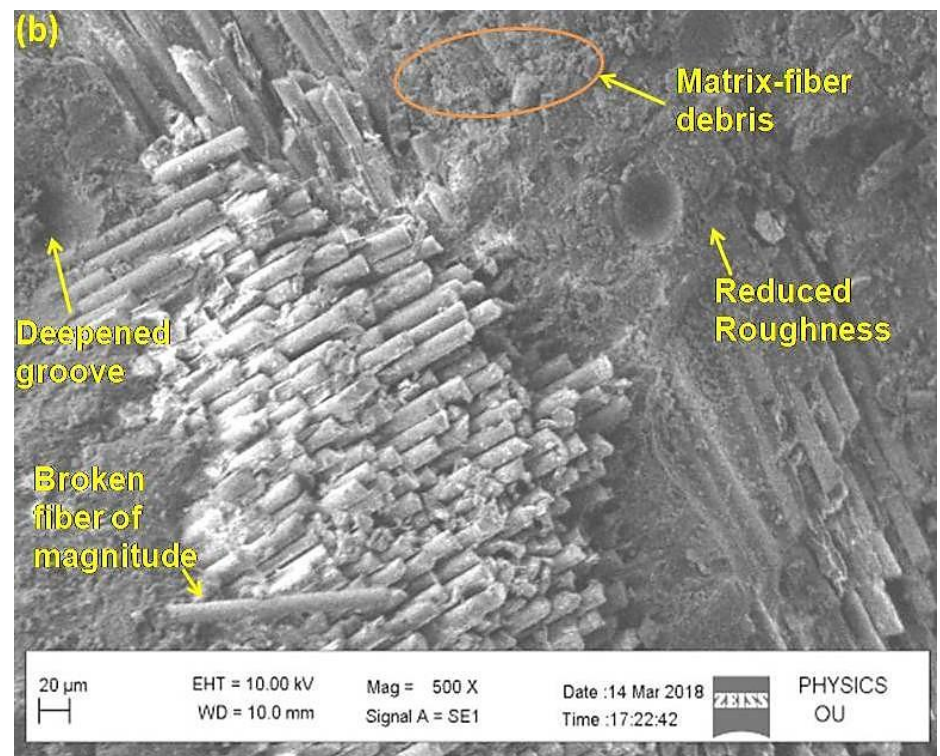

Figure 7(b). SEM image of specimen tested at $2 \mathrm{gm} / \mathrm{min}, 30^{\circ}$ impinging angle, $2 \mathrm{bar}$ pressure, $1 \mathrm{~min}$ holding period, $30 \mathrm{~mm}$ stand-off distance for compositions $0.5 \mathrm{wt} . \%, 21$ vol. $\%, 45^{\circ} / 45^{\circ}$ 


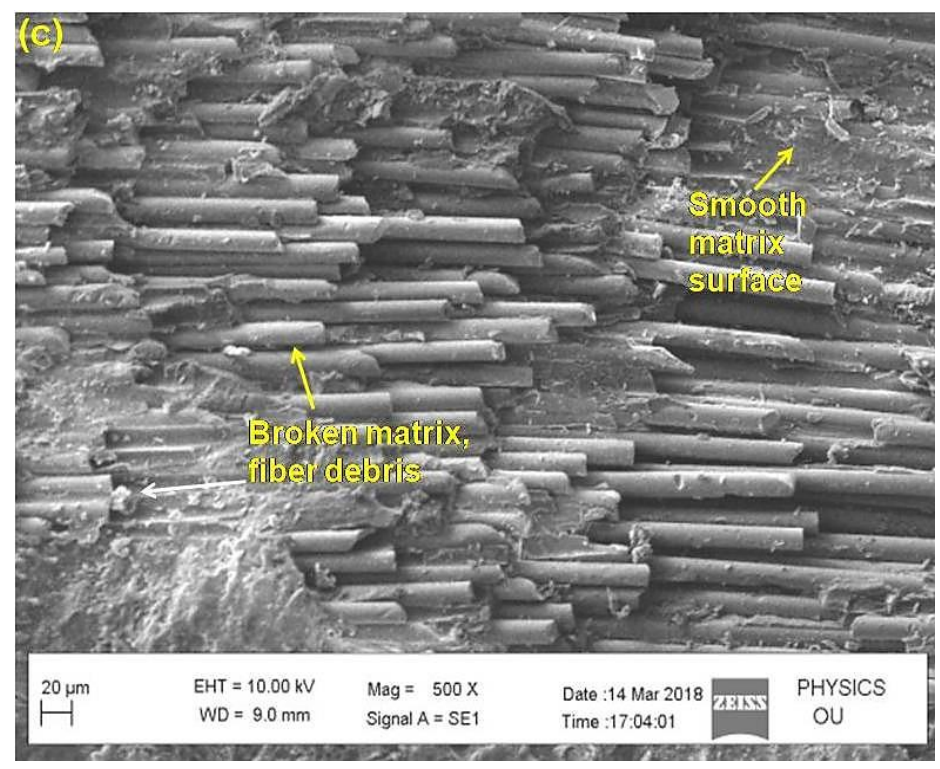

Figure 7(c). SEM image of specimen tested at $2 \mathrm{gm} / \mathrm{min}, 30^{\circ}$ impinging angle, $2 \mathrm{bar}$ pressure, $1 \mathrm{~min}$ holding period, $30 \mathrm{~mm}$ stand-off distance for compositions $2.5 \mathrm{wt} . \%, 21 \%$, $45^{\circ} /-45^{\circ}$

Figures 8(a) - 8(b) show that at $15^{\circ}$ impingement angle, deformation occurred due to the ploughing effect caused by hitting sand particles. However, the $\mathrm{E}_{\mathrm{r}}$ at $15^{\circ}$ angle of impingement is low when compared to $\mathrm{E}_{\mathrm{r}}$ value obtained at $60^{\circ}$ angle of impingement as the ploughing effect is considerably low. The deformation of the material due to the ploughing effect indicates the semi-brittle nature of the composite. This effect increases with an increase in angle from $15^{\circ}-60^{\circ}$ and decreases from $60^{\circ}-90^{\circ}$ [35]. The increase in the sand flow rate increases the number of particles hitting the unit surface area, thereby increasing $\mathrm{E}_{\mathrm{r}}$.

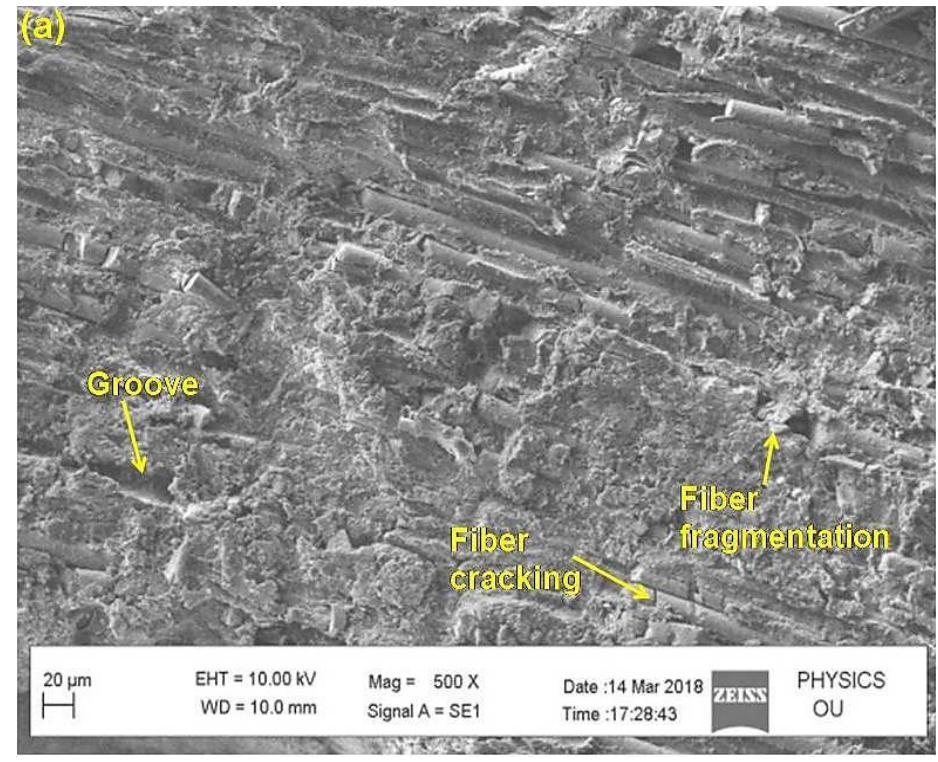

Figure 8(a). SEM image of test specimen tested at $2 \mathrm{gm} / \mathrm{min}, 15^{\circ}$ angle, 2 bar, $1 \mathrm{~min}, 10 \mathrm{~mm}$ 


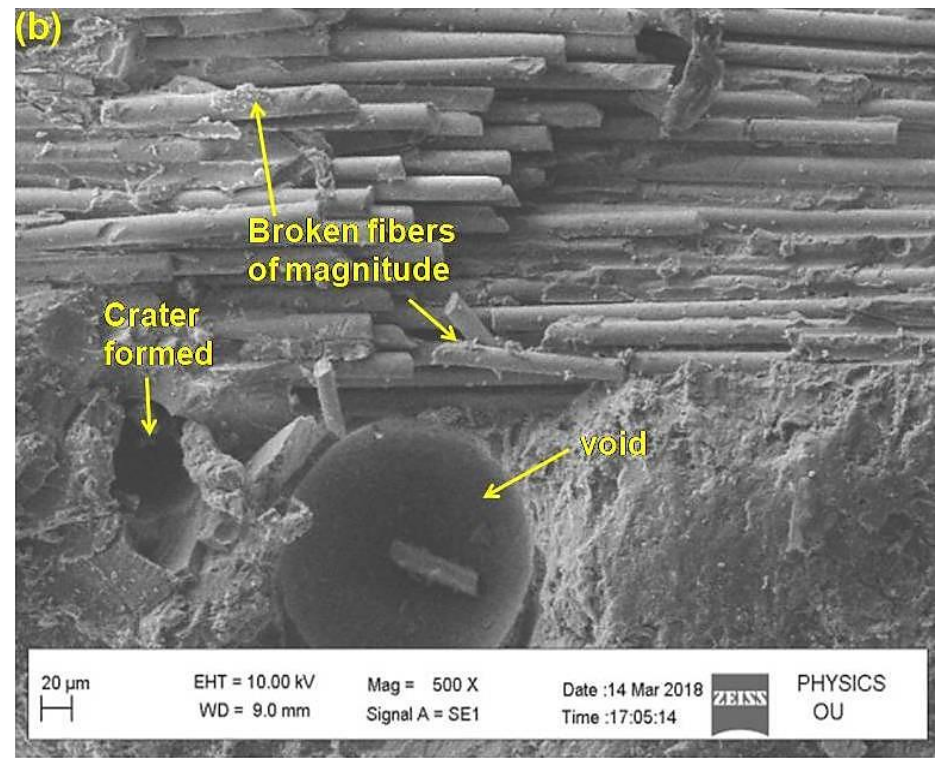

Figure 8(b). SEM image of test specimen tested at $2 \mathrm{gm} / \mathrm{min}, 15^{\circ}$ angle, 2 bar, $3 \mathrm{~min}, 30 \mathrm{~mm}$

Table 15 shows that $f$ is the highest contributing factor to $\mathrm{E}_{\mathrm{r}}$. As the air stream pressure increases, the kinetic energy of the sand particles increases resulting in formation of cracks followed by breaking of matrix and fibers, and it is the third highest contributing factor to $\mathrm{E}_{\mathrm{r}}$ $[14,15,27]$. Figures 8(c) - 8(d) show that the combined effect of all the three major contributing factors at their maximum levels resulted in the deeply eroded region compared to the partially eroded surface shown in Figures 8(a) - 8(b), where lower levels of the same factors were used. From Figures $8(\mathrm{c})-8(\mathrm{~d})$ it is obvious that at 6 bar pressure, the deformation is more pronounced on the surface as deeper grooves are formed unlike the shallow grooves observed in Figures 8(a) - 8(b). The effect of the parameters $t, d$ was low compared to the first three, which is also confirmed by the low percentage contributions exhibited by these factors shown in Anova Table 15. 


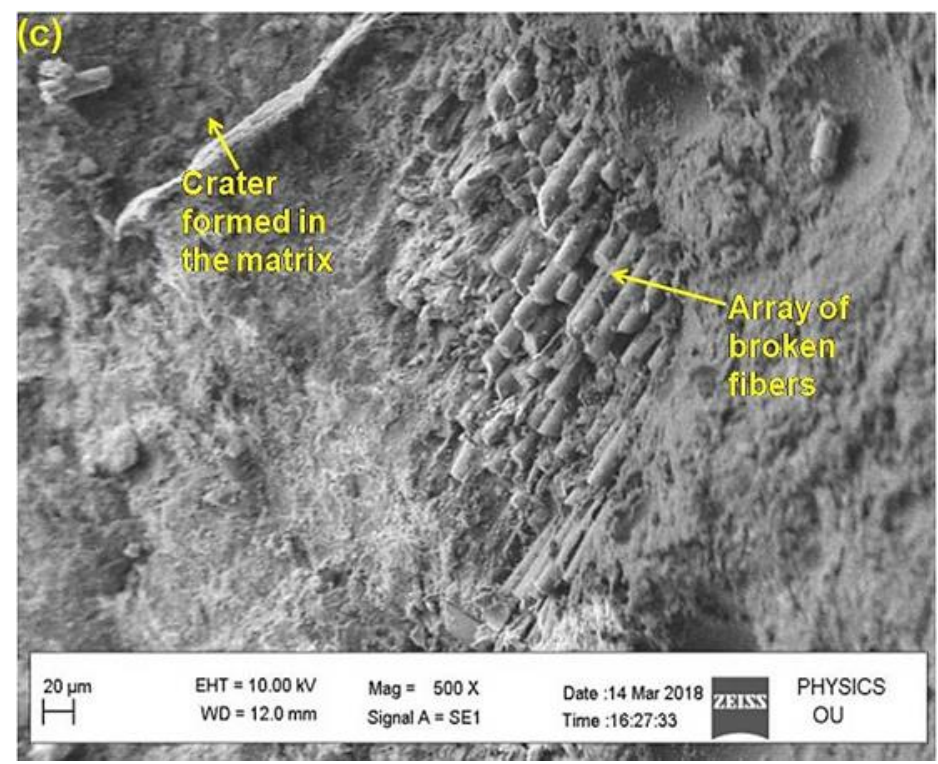

Figure 8(c). SEM image of test specimen tested at $4 \mathrm{gm} / \mathrm{min}, 60^{\circ}$ angle, 6 bar, $1 \mathrm{~min}, 10$ $\mathrm{mm}$.

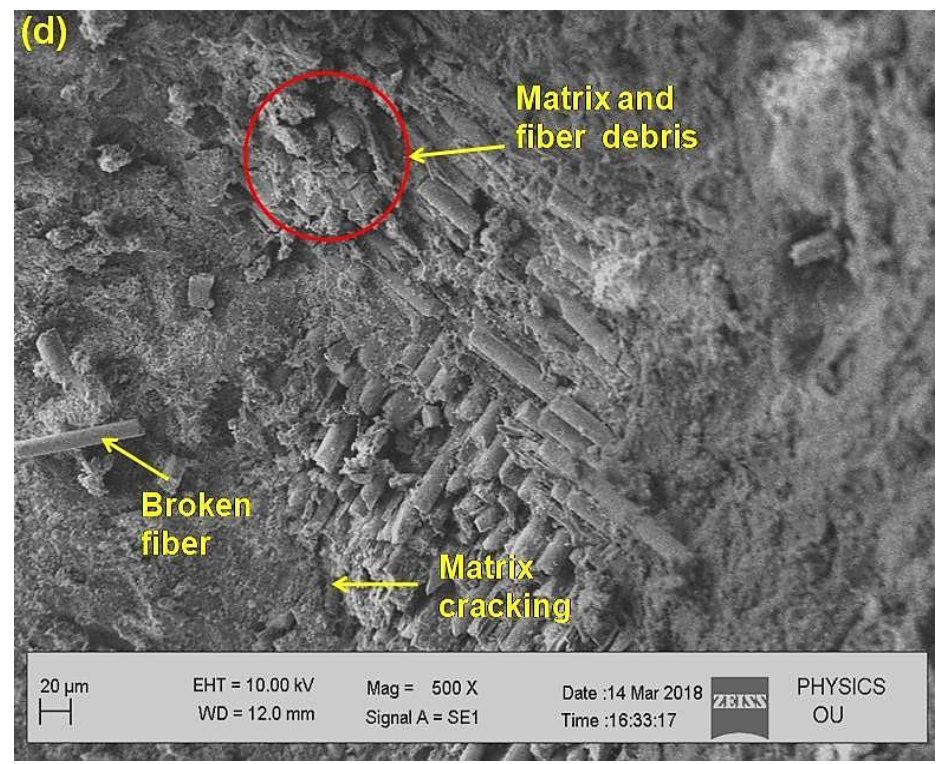

Figure 8(d). SEM image of test specimen tested at $4 \mathrm{gm} / \mathrm{min}, 60^{\circ}$ angle, 6 bar, $3 \mathrm{~min}, 30 \mathrm{~mm}$. 


\section{CONCLUSION}

- $\quad$ The microhardness of the EGCNs is governed mainly by nanoclay and glass fiber reinforcement, but the fiber orientation has a negligible effect. The highest hardness observed is $27.23 \mathrm{HV}$ at $2.5 \mathrm{wt} \%$ nanoclay, $31.5 \mathrm{vol} \%$ glass fiber, and $0^{\circ} / 90^{\circ}$ which is $56 \%$ higher compared to neat glass-epoxy.

- $\quad$ The lowest erosion rate observed is $1865 \mathrm{mg} / \mathrm{kg}$ at $2.5 \mathrm{wt} \%$ nanoclay, $10.5 \mathrm{vol} \%$ glass fiber, and $45^{\circ} / 45^{\circ}$ fibers orientation at the fixed testing conditions of $2 \mathrm{gm} / \mathrm{min}$ sand flow rate, $30^{\circ}$ impingement angle, 2 bar air stream pressure, 1 min holding period, $30 \mathrm{~mm}$ stand-off distance. It is $29.5 \%$ lower compared to the neat glass-epoxy composite.

- $\quad$ The lowest erosion rate observed is $1586 \mathrm{mg} / \mathrm{kg}$ under testing conditions of $2 \mathrm{gm} / \mathrm{min}$ sand flow rate, $15^{\circ}$ impingement angle, 2 bar air stream pressure, 1 min holding period and $30 \mathrm{~mm}$ stand-off distance. It is $29.8 \%$ lower compared to neat glass-epoxy composite.

- $\quad$ SEM micrography has shown that with an increase in nanoclay content the surface roughness of the eroded surface greatly reduced indicating slow erosion. Irrespective of increased hardness, the increase in fiber content increased the erosion rate as the fibers broke into sizes much bigger than the matrix and expelled from the zone.

- $\quad$ At high pressure, high sand flow rate, high testing period, low stand-off distance and at $60^{\circ}$ impinging angle, the surface has shown deeply eroded zones.

\section{REFERENCES}

[1] Shokrieh MM, Omidi MJ. Tension behavior of unidirectional glass/epoxy composites under different strain rates. Composite Structures 2009; 88 (4): 595-601.

[2] Panda P, Mantry S, Mohapatra S, Singh SK. A study on erosive wear analysis of glass fiber - epoxy - AlN hybrid composites. Journal of Composite Materials 2014; 48 (1): 107-18.

[3] Finnie I. Some observations on the erosion of ductile metals. Wear 1972; 19: 81-90.

[4] Aglan HA CJT. Erosion damage features of polyimide thermoset composites. SAMPEQ 1993:41-7.

[5] Biswas S, Satapathy A. Tribo-performance analysis of red mud filled glass-epoxy composites using Taguchi experimental design. Materials and Design 2009; 30 (8): 2841-53.

[6] Mohapatra S, Mantry S, Singh SK, Satapathy A. Solid particle erosion behavior of glass-epoxy composites filled with $\mathrm{TiC}$ derived from ilmenite. International Journal of Plastics Technology 2014;18 (1): 75-87.

[7] Mahapatra SS, Patnaik A, Satapathy A. Taguchi method applied to parametric appraisal of erosion behavior of GF-reinforced polyester composites. Wear 2008; 265 (1-2): 214-22.

[8] Harsha AP, Jha SK. Erosive wear studies of epoxy-based composites at normal incidence. Wear 2008; 265 (7-8): 1129-35.

[9] Jerold S, Chelladurai S, Arthanari R. Effect of Copper Coating and Reinforcement 
Orientation on Mechanical Properties of LM6 Aluminium Alloy Composites Reinforced with Steel Mesh by Squeeze Casting. Transactions of the Indian Institute of Metals 2018; 71 (5): 1041-8.

[10] Samuel Chelladurai SJ, Arthanari R, Krishnamoorthy K, Selvaraj KS, Govindan P. Investigation of the mechanical properties of a squeeze-cast LM6 aluminium alloy reinforced with a zinc-coated steel-wire mesh. Materials and Technology 2018; 52 (2): 125-31.

[11] Jerold S, Chelladurai S, Arthanari R, Nithyanandam N. Investigation of Mechanical Properties and Dry Sliding Wear Behaviour of Squeeze Cast LM6 Aluminium Alloy Reinforced with Copper Coated Short Steel Fibers. Transactions of the Indian Institute of Metals 2018; 71 (4): 813-22.

[12] Samuel Chelladurai SJ, Arthanari R, Selvarajan R, Athanarsamy S, Arumugam S, Veerakumar G. Investigation on Mechanical Properties and Wear Behaviour of Squeeze Cast LM13 Aluminium Alloy Reinforced with Copper Coated Steel Wires 1 Introduction. Zeitschrift Für Physikalische Chemie 2018: 1-20.

[13] Samson Jerold SC, Ramesh A, Narippalayam Thangaraj A, Sekar H. Dry sliding wear characterization of squeeze cast $\mathrm{LM} 13 / \mathrm{FeCu}$ composite using response surface methodology. China Foundry 2017; 14 (6): 525-33.

[14] Papadopoulos A, Gkikas G, Paipetis AS, Barkoula N. Effect of CNTs addition on the erosive wear response of epoxy resin and carbon fibre composites. Composites: Part A 2016; 84: 299-307.

[15] Briscoe BJ. The Tribology of Composites Materials: A Preface. Composite Materials Series 1993; 8: 3-15.

[16] Miyazaki N, Takeda N. Solid Particle Erosion of Fiber Reinforced Plastics. Journal of Composite Materials 1993; 27 (1): 21-31.

[17] Miyazaki N, Hamao T. Solid Particle Erosion of Thermoplastic Resins Reinforced by Short Fibers. Journal of Composite 1994; 28 (9): 871-83.

[18] Harsha AP, Tewari US, Venkatraman B. Solid particle erosion behaviour of various polyaryletherketone composites. Wear 2003; 254 (7-8): 693-712.

[19] Fouad Y, El-Meniawi M, Afifi A. Erosion behaviour of epoxy based unidirectionl (GFRP) composite materials. Alexandria Engineering Journal 2011; 50 (1): 29-34.

[20] Bagci M, Imrek H. Application of Taguchi method on optimization of testing parameters for erosion of glass fiber reinforced epoxy composite materials. Materials and Design 2013; 46: 706-12.

[21] Mohan N, Mahesha CR, Rajaprakash BM. Erosive wear behaviour of WC filled glass epoxy composites. Procedia Engineering 2013; 68: 694-702.

[22] Bagci M, Imrek H. Solid particle erosion behaviour of glass fibre reinforced boric acid filled epoxy resin composites. Tribology International 2011; 44 (12): 1704-10.

[23] Bagci M. Determination of Solid Particle Erosion with Taguchi Optimization Approach of Hybrid Composite Systems. Tribiology International 2015.

[24] Senthil Kumar MS, Mohana Sundara Raju N, Sampath PS, Vivek U. Tribological analysis of nano clay/epoxy/glass fiber by using Taguchi's technique. Materials and Design 2015; 70: 1-9.

[25] Haque A, Shamsuzzoha M, Hussain F, Dean D. S2-glass/epoxy polymer nanocomposites: Manufacturing, structures, thermal and mechanical properties. Journal of Composite Materials 2003; 37 (20): 1821-38. 
[26] Kornmann X, Rees M, Thomann Y, Necola A, Barbezat M, Thomann R. Epoxylayered silicate nanocomposites as matrix in glass fibre-reinforced composites. Composites Science and Technology 2005; 65 (14): 2259-68.

[27] Lin LY, Lee JH, Hong CE, Yoo GH, Advani SG. Preparation and characterization of layered silicate/glass fiber/epoxy hybrid nanocomposites via vacuum-assisted resin transfer molding (VARTM). Composites Science and Technology 2006; 66 (13): 2116-25.

[28] Bozkurt E, Kaya E, Tanoğlu M. Mechanical and thermal behavior of non-crimp glass fiber reinforced layered clay/epoxy nanocomposites. Composites Science and Technology 2007; 67 (15-16): 3394-403.

[29] Manfredi LB, De Santis H, Vázquez A. Influence of the addition of montmorillonite to the matrix of unidirectional glass fibre/epoxy composites on their mechanical and water absorption properties. Composites Part A: Applied Science and Manufacturing 2008; 39 (11): 1726-31.

[30] Shi Y, Kanny K, Jawahar P. Hybrid nanocomposites: Processing and properties. Advanced Composite Materials 2009; 18 (4): 365-79.

[31] ASTM E 384. Standard Test Method for Microindentation Hardness of Materials. ASTM International 2017; USA.

[32] Taguchi, G., and Konishi S. Taguchi Methods, Orthogonal Arrays and Linear Graphs, Tools for Quality Engineering. American Supplier Institute 1987: 35-38.

[33] Patnaik A, Satapathy A, Mahapatra SS, Dash RR. A modeling approach for prediction of erosion behavior of glass fiber-polyester composites. Journal of Polymer Research 2008; 15 (2): 147-60.

[34] Alomayri T, Low IM. Synthesis and characterization of mechanical properties in cotton fiber-reinforced geopolymer composites. Journal of Asian Ceramic Societies 2013; 1 (1): 30-4.

[35] Harsha AP, Jha SK. Erosive wear studies of epoxy-based composites at normal incidence. Wear 2008; 265: 1129-35.

[36] Srivastava VK, Pawar AG. Solid particle erosion of glass fibre reinforced fly ash filled epoxy resin composites. Composites Science and Technology 2006; 66 (15): 3021-8. 